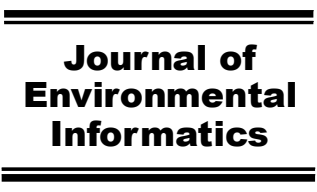

www.iseis.org/jei

\title{
Spatial Distribution Patterns of Eurasian Otter (Lutra Lutra) in Association with Environmental Factors Unravelled by Machine Learning and Diffusion Kernel Method
}

\author{
S. Hong ${ }^{1,2}$, T.-S. Chon ${ }^{3,4}$, and G. J. Joo ${ }^{*}$ \\ ${ }^{1}$ Department of Animal Science and Biotechnology, Kyungpook National University, Sangju 37224, Republic of Korea \\ ${ }^{2}$ Department of Horse, Companion, and Wild Animal Science, Kyungpook National University, Sangju 37224, Republic of Korea \\ ${ }^{3}$ Department of Forest Environment Protection, College of Forest and Environmental Sciences, Kangwon National University, \\ Chuncheon 25931, Republic of Korea \\ ${ }^{4}$ Ecology and Future Research Association, Busan 46228, Republic of Korea \\ ${ }^{5}$ Department of Biological Sciences, Pusan National University, Busan 46241, Republic of Korea
}

Received 25 March 2019; revised 08 May 2019; accepted 09 July 2019; published online 24 September 2020

\begin{abstract}
In South Korea, the endangered Eurasian otter (Lutra lutra) populations have been recovered throughout the country. To examine the status of otter populations, we monitored spraint densities at $250 \sim 355$ sites annually from 2014 to 2017 in the Nakdong River basin. The diffusion kernel method was applied to both binary and continuous spraint data. Two geographical populations were identified: northern and southern populations. The northern population continuously increased over a broad area from north to south during the study period. In contrast, the southern population narrowly dispersed, limited by its location in an industrial area. The spatial self-organizing map (Geo-SOM) revealed associations between spraint densities and environmental factors by correlating the geographic locations of the sampling sites. Both populations were negatively affected by anthropogenic factors, including proximity to factories and human population density. However, cumulative association of all environmental factors, including landscape, food sources, and anthropogenic factors, were noted in 2016 after which otter populations fully recovered. Population development stabilized while exhibiting an overall high association with environmental factors. The results of the diffusion kernel method and data variation according to the Geo-SOM consistently presented substantial change in population dispersal (i.e. the merge of two subpopulations, and complete associations between spraint and environmental factors). The combination of the diffusion kernel method and Geo-SOM was effective in portraying temporal changes in population states in association with environmental factors based on spraint data in the last phase of full recovery.
\end{abstract}

Keywords: Dispersal; recovery; spraints; habitat preference; conservation; Republic of Korea

\section{Introduction}

Eurasian otter (Lutra lutra) populations have been recovered worldwide, particularly in Europe (Mason and Macdonald, 2004; Elmeros et al., 2006; Janssens et al., 2006; Prigioni et al., 2007; Clavero et al., 2010). In Korea, otter population recovery is a current issue (Hong et al., 2017, 2018). Industrial development and economic growth occurred rapidly in South Korea beginning in the 1960s, leading to a simultaneous decrease in wildlife (Won and Smith, 1999). However, efforts have been made to improve ecological conservation and restoration, as well as increase public awareness and social concern for ecosystem services, particularly since

* Corresponding author. Tel.: +82-51-512-2262.

E-mail address: tschon.chon@gmail.com (T.-S. Chon).

${ }^{*}$ Corresponding author. Tel.: +82-51-510-2258; fax: +82-51-581-2962.

E-mail address: gjjoo@pusan.ac.kr (G. J. Joo).

ISSN: 1726-2135 print/1684-8799 online

(C) 2020 ISEIS All rights reserved. doi:10.3808/jei.202000443 the 1988 Olympics (Hong et al., 2017). The regional establishment and dispersal of otter populations in Korea have been reported by Hong (2016). However, there is no report specifically addressing the relationship between otter populations and environmental factors in the short period spanning the final phase of recovery. We present a recent case of otter populations developing rapidly to reach full recovery in the survey area within Korea. We surveyed population dispersal and measured environmental factors on an annual basis from 2014 to 2017. To extract information from the complex data representing population dynamics, we applied two computational methods: diffusion kernel to reveal dispersal patterns, and a spatial self-organizing map (Geo-SOM) to address the effects of environmental factors on recovery.

Spatial dispersal patterns were surveyed on a fine scale ( 0.02 sites per $\mathrm{km}^{2}$ ) over the course of full recovery for otters in Nakdong River basins. Previous research on the recovery of otter populations examined longer intervals ( $5 \sim 10$ years) using coarse spatial scales (Cortés et al., 1998; Elmeros et al., 
2006; Prigioni et al., 2007). Furthermore, the data were mainly binary (presence/absence at the sampled areas), whereas our observation data are quantitative, comprised of spraint densities.

We started investigating spatial distributions using a statistical approach that provided utilisation distributions in relation to home range (Hayne, 1949; Calhoun and Casby, 1958; Van Winkle, 1975), a multiscale random walk (Loehle, 1990; Gautestad and Mysterud, 1993), and Monte Carlo simulations (Boulanger and White, 1990; Naef-Daenzer, 1993). Additionally, an approach has been reported useful for estimating spatial distribution patterns for single time point data according to pair-wise spatial correlations (Keeling et al., 2004). Ultimately, a kernel density estimator, a valuable tool for analysing complex data (e.g., non-normal or multimodal) (Silverman, 1986; Doucet et al., 2001), was used to address spatial visualisation of population distribution.

To provide a closer examination of dispersal dynamics, nonparametric models were further developed. The diffusion kernel method is an effective tool provided that local sample data are interpolated over the entire spatial domain (Chen, 1996; Blundell et al., 2001; See Seaman and Powell (1996) for review on ecological applications of the kernel density estimator). The kernels were devised to address diffusion processes as a special class of exponential kernel based on the heat equation, regarded as a discretisation of the Gaussian kernel over discrete structures (Kondor and Lafferty, 2004; Botev et al., 2010).

In this study, we intended to use spraint densities to represent population dispersal patterns. The use of faecal densities in the estimation of otter populations and those of other Mustelids and carnivores has been studied extensively (Hutchings and White, 2000; Webbon et al., 2004). Because Eurasian otters primarily live and forage along streams, their home ranges tend to be linear in shape (Erlinge, 1967). However, faecal densities are also subject to uncertainty in the representation of population densities. Spraint production per individual is not well known (Green et al., 1984), and unknown proportions of spraints may be defecated in the water. For these reasons, some otter specialists deem spraints a poor method for monitoring otter populations (Kruuk and Conroy, 1987).

To resolve this problem, namely spraints data insufficiently representing population dispersal, we opted for a stepby-step approach in utilization of data for spraint densities. We provided two types of data, binary and continuous, to present dispersal patterns of otter populations. Initially, we translated the continuous data into binary data (see 'Dispersal patterns based on diffusion kernel' section in Materials and Methods): the transformed data only represented either existence or absence of otters, not population density. After applying the binary data, we further discussed the possibility of using the continuous data as a means of presenting population dispersal patterns. According to Mowry et al. (2011), spraint densities of otters are linearly and positively related with population densities; although the species used in the referenced study differs from the species surveyed in our study, feeding and defecating behaviours are widely known to be similar (Rostain et al., 2004; Kruuk, 2006). Given that spraint densities are proportional to population densities and the surveys were conducted by the same surveyor with the same protocol during the study period (see Materials and Methods), we could hypothesise that the spraint densities were effective means for representing relative densities. Although absolute densities were not known, the data was suspected to sufficiently depict the overall population trend (increase/decrease) throughout the survey area.

We also investigated the relationship between otter populations and environmental factors during the course of recovery. Numerous environmental factors are involved in determining the distribution of otter populations, including landscape, food source, and anthropogenic disturbances (Cortés et al., 1998; Barbosa et al., 2003; Ruiz-Olmo et al., 2005, 2009, 2011; Marcelli and Fusillo, 2009; Clavero et al., 2010). With respect to landscape factors, the proportion of riparian forest (Janssens et al., 2006; Van Looy et al., 2014; Zhang et al., 2016), stream density (Prenda et al., 2001), vegetation cover (Scorpio et al., 2016), and altitude (Jo et al., 2017) were reported to be of notable importance for otter populations.

To analyse the relationship between spraint data and environmental factors, we used a machine learning technique. Data for spraints and related environmental factors are complex and could not be easily analysed using simple methods such as linear regression (Kruuk, 2006; Cho et al., 2009). Instead, we used the self-organizing map (SOM) method to extract features from complex ecological data (Chon et al., 1996, 2000; Cho et al., 2009; See Chon (2011) regarding SOM ecological application). Further, we utilised a SOM that included geographic information: the Geo-SOM. This technique, developed by Bação et al. (2004), adds the geographical location of sample sites to the SOM algorithm for training (Bacão et al., 2004, 2005). In this study, we attempted to demonstrate that associations between otter populations and environmental factors were effectively portrayed by the geographic locations of sample sites based on Geo-SOM during the course of recovery.

Employing the fine-scale dispersal data, we aimed to (1) define population dispersal patterns of otters during the last phase of full recovery in the Nakdong River basin, Korea, by applying diffusion kernel to the spraint data in field conditions, and (2) identify important environmental factors associated with otter populations using Geo-SOM.

\section{Materials and Methods}

\subsection{Study Area}

The Nakdong River, occupying a principal watershed area in South Korea, flows approximately $520 \mathrm{~km}$ north to south with a catchment covering approximately $23,800 \mathrm{~km}^{2}$ (a quarter of South Korea's land area), as illustrated in Figure 1. Approximately $60 \%$ of annual rainfall occurs during the short wet period from June to September (Jeong et al., 2007). The 
environment of the river basin has seen substantial improvement regarding forest development and water quality due to effective social campaigns and civil efforts (Hong et al., 2017). Consequently, the improved environmental conditions were suitable for the recovery of otter populations (Hong, 2018). Until the beginning of the $21^{\text {st }}$ century, there were two otter populations located in different areas within the Nakdong River basin, partitioned into northern and south-western areas. The two separate populations originated as parts of two other populations in South Korea: south-central and northeastern populations (Hong, 2018).

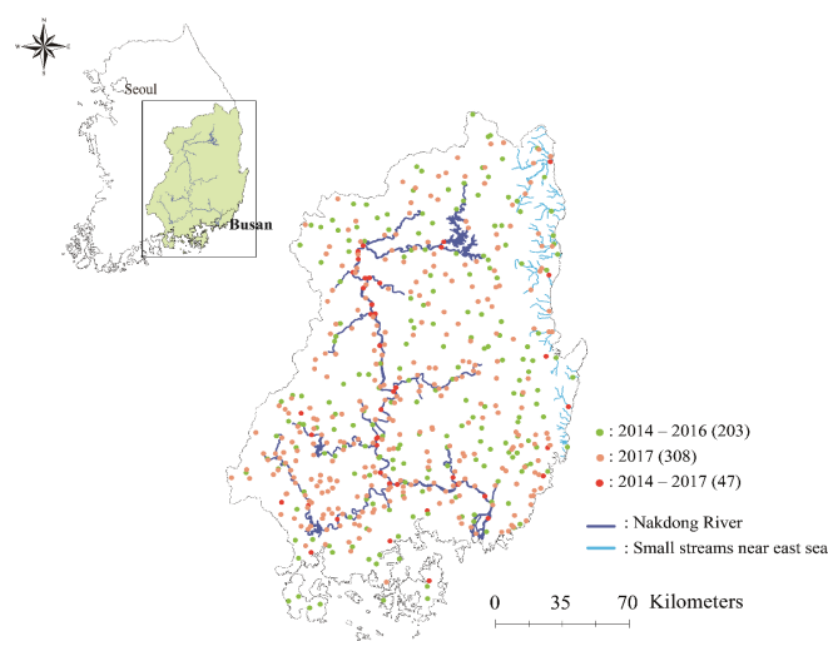

Figure 1. Study area. 250 sites between 2014 and 2016, and 355 sites during 2017 in the Nakdong River basin. Red circles (47 sample sites) represent the consistent sites throughout survey periods (2014 2017). Light green (203 sample sites) and light red circles (308 sample sites) represent the survey sites from 2014 to 2016 and 2017, respectively. Dark and light blue lines show the main river and tributaries of local rivers near the east coast, respectively. The upper left panel shows South Korea, and the light green area in the rectangle represent the Nakdong River basin.

\subsection{Spraint Density Measurement}

Otter spraints were observed along the main trajectories of the Nakdong River. Along a 600 m transect, we recorded the starting point of each sample site and searched for spraints underneath bridges, rocks, and artificial concrete structures (Kruuk, 2006). We spent approximately 40 minutes to count the number of spraints per sample site. After sampling, we converted the number of spraints into indices of abundance (number of spraints per metre). At each site where spraints were collected, a GPS reading (GPSMAP 64s, GARMIN) was taken to measure the distance from the starting point. All surveys were conducted by the same experienced surveyor. For 45 days (May $1^{\text {st }}$ to June $15^{\text {th }}$ ) each year from 2014 to 2016, 250 sample sites were observed. In the same 45-day period of 2017, the survey was conducted at 355 sample sites to fulfil the objective of the research project (MOE/NIER, 2017) that suggests examination of dispersal degree over a broad area in the last year of the survey.

\subsection{Environmental and Biological Variables}

To characterize biological and environmental factors associated with otter recovery, landscape, food source, and anthropogenic stressors were selected considering previous reports on otter habitat preference (Cortés et al., 1998; Barbosa et al., 2003; Cho et al., 2009), as stated above. We included forest, water area, vegetation, and altitude for the survey in this study. In addition to the proportion of riparian forest, we also observed distance to the forest, as this factor was previously related to otter presence in the mountainous area (Teresa et al., 2014; Scorpio et al., 2016). The two landscape factors, densities of water areas (streams, lakes, rivers, offshore seas, and dams) and riparian forests, within the buffer area $\left(2.5 \mathrm{~km}\right.$ radius; $15 \mathrm{~km}^{2}$ indicating adult male home range; Erlinge, 1967; Min, 2007) were added using the join tools of ArcMap 10.5 (ESRI, USA).

For food sources, we used the number of fish individuals (NFI), Fish Assessment Index (FAI), and Benthic MacroInvertebrate Index (BMI). The number and biomass of fish plays an important role in determining population dispersal, abundance (Sjoasen, 1997; Barbosa et al., 2003; Cho et al., 2009), and stability for otters (Ruiz-Olmo et al., 2005, 2009, 2011; Vergara et al., 2014). We could not include biomass due to limited data and substantial measurement effort. FAI is an index representing ecosystem health based on fish species composition; while the number of fishes indicates the amount of food available for otters, FAI indicates whether or not the habitat conditions at the sample area are suitable for otters (Hong et al., 2018). In addition, to account for the food chain of otter populations in this study, we included a BMI index that considers benthic macroinvertebrates as a food source for fish.

Anthropogenic factors are reported as a major constraint to increasing the population abundance and distribution of otters (Conroy et al., 1998, 2000; Robitaille and Laurence, 2002; Zhang et al., 2016; Hong et al., 2017). Human population density (Robitaille and Laurence, 2002), distance to residence (Cho et al., 2009), road densities (Robitaille and Laurence, 2002), and traffic rates (Jo et al., 2017) have previously been recorded as important factors. We selected human population density (Hong et al., 2018) and distance to residential area (Cho et al., 2009). Marcelli and Fusillo (2009) reported that industrial areas had a negative impact on otter distribution. Considering a large proportion of the survey area was occupied by industry, we also included distance to factory areas. Road densities, however, were not included in this study as the sample sites were within $600 \mathrm{~m}$ of the river and the roads were mostly nearby (sampling largely started from a bridge over the river); therefore, the effect of roads could not be differentiated at such a narrow range in this study. The residential and factory areas were determined using land cover maps $(1 \times 1 \mathrm{~m}$ resolution) distributed by the Ministry of Environment based on satellite remote sensing imagery (2010 2013). 
The sample sites were selected according to the Stream Health project by the Korean government (MOE/NIER, 2017). Bio-integrity was measured by assessing aquatic organisms (benthic diatoms, benthic macroinvertebrates, and fish) and canopy cover. Of the indices, we utilised altitude, canopy cover rate $(\%)$, BMI, FAI, and the number of fish individuals based on the survey by MOE/NIER (2017) (Hong et al., 2018). In 2017, the canopy cover rate was excluded due to a partial change in the project objective (MOE/NIER, 2017). The BMI and FAI were scored based on indicator and diversity values, ranging from 0 to 100 (MOE/NIER, 2017). The equations for calculating the indices are shown in Appendices S1 S4.

Three variables expressing anthropogenic stress were also measured, including distance to factory, distance to residence, and human population density within the buffer area. The distances from the variables, including distance to mountains, were calculated to the nearest metre with a GIS tool (Arc Map 10.5, ESRI, USA). The land cover maps were provided by the Ministry of Environment, EGIS from 2011 to 2014 at a $1 \mathrm{~m}$ resolution. The human population size (100 m resolution) was provided by BIZ-GIS (http://www.biz-gis.com). The data for all variables were log-transformed (with the exception of BMI and FAI) and normalised $[0,1]$ according to the minimum and maximum for each variable per year.

\subsection{Data Analysis}

\subsubsection{Dispersal Patterns Based on Diffusion Kernel}

Diffusion kernel was applied to the binary and continuous spraint data to address population dispersal patterns over the course of recovery during the survey period between 2014 and 2017 (Kondor and Lafferty, 2004). Initially, binary data were produced from the continuous data. If at least one spraint was found at the sampling site, we considered otter present in the survey area (Presence, 1), otherwise the sampling site had no otter (Absence, 0). Accordingly, the uncertainty inherent in using continuous values of spraint densities to represent population densities would be alleviated: the transformed data only represented either existence or absence of otters, not population densities. Given the large number of sample sites surveyed on a fine-scale over a broad survey area, the simple presence/absence data could present population dispersal patterns. The diffusion kernel method was applied to the binary data (Seaman and Powell, 1996; Botev et al, 2010). After analysing the binary data, diffusion kernel was subsequently applied to the continuous data (number of spraints per $600 \mathrm{~m}$ ), assuming the linear relationship between spraint and population densities (Mowry et al., 2011; See 'Introduction').

The interpolation processes for applying diffusion kernel are outlined below (ArcGIS, http://pro.arcgis.com). The search radius was determined according to the formula:

$$
\sqrt{\frac{20}{\pi}\left(\frac{A}{N}\right)}
$$

where $A$ is the rectangular area that minimally covers the sur- vey area $\left(46,101 \mathrm{~km}^{2}\right.$ in $2014 \sim 2016$ and $42,384 \mathrm{~km}^{2}$ in 2017$)$, $N$ is the total number of samples surveyed annually (250 in $2014 \sim 2016$ and 355 in 2017), and $\pi$ is the circle rate. In our study, the radius was $34.26 \mathrm{~km}$ in $2014 \sim 2016$ and $27.57 \mathrm{~km}$ in 2017.

We applied diffusion kernel to the spraint data in two ways. First, environmental conditions were assumed to be homogenous in the Nakdong River basin, where the cost of dispersal remained constant over the whole survey area. Second, barriers to otter population dispersal were assumed to depend on land type. Diffusion kernel effectively addresses dispersal differentiation in heterogeneous environments with different costs to barrier crossing (ArcGIS 10.5); the cost of travel was considered as a source of spatial heterogeneity. In our study, the travel cost was assigned to urban areas which is the primary limiting factor in otter dispersal (Marcelli and Fusillo, 2009). The index of urbanisation, used as the weight for the cost, was measured with the focal statistics of ArcGIS 10.5. The number of cells $(10 \times 10 \mathrm{~m}$ resolution $)$ occupied by the urban area was determined per $1 \mathrm{~km}$ radius circle on the map in which industrial areas were defined (Ministry of Environment, $2010 \sim 2013$; Figure 2c). The cell numbers for the urban area varied between 0 and 279 . The numbers were divided into nine groups $(1: 0 \sim 4,2: 4 \sim 12,3: 12 \sim 26,4: 26 \sim$ 45, 5: $45 \sim 68,6: 68 \sim 94,7: 94 \sim 125,8: 125 \sim 164,9: 164 \sim$ 279) according to the Jenks optimisation method (de Smith et al., 2007). The newly classified numbers were then regarded as cost values that served as a barrier for otter dispersion. The weight of the cost was used to respectively enlarge the cell distance; if the cost was high, the distance between the cells was increased. More diffusion processes were required based on the enlarged distances on the map, represented as additive barriers (http://pro.arcgis.com; Krivoruchko and Gribov, 2002):

Barrier $=($ average cost value in the neighbouring cells $) \times$ (distance between cell centre)

\subsubsection{Application of Geo-SOM to Identify Spraint Density Relationships}

SOM is a learning algorithm used in artificial neural networks without supervision (without knowledge a priori), also frequently referred to as a Kohonen network (Kohonen, 1982; Chon et al., 1996). Although the SOM can be used mainly for training biological/environmental factors, additional information on geographical location could be accommodated in the Geo-SOM, which has been devised in such a manner that variables of sample sites are trained to geographic tolerance (Bação et al., 2005).

Specifically, two processes are performed in the GeoSOM. Initially, the geographic information is trained for each sample unit, and the sample sites of the closest corresponding unit are selected based on the geographic tolerance $k$. Only the sample sites chosen by geographic training are used for training with environmental variables in the next round of the SOM. The detailed calculation processes for the Geo-SOM are described by Bação et al. (2005). 
Parameter $k$ defines the radius magnitude in the output spaces with spatial influence at low levels of tolerance (Bação et al., 2005). As $k$ (e.g., $1 \sim 12$ ) increases, the radius of the neuron will also increase and more broadly cover the spatial range, consequently ensuring that geographic relationships with neighbouring vectors during training are to a large extent forced (see Bação et al. (2005) for detailed calculation processes of the Geo-SOM). In this study, we used the geographic tolerance $k=0$ with the maximum geographic effect. Slight variations were observed when different levels of $k$ between 0 and 12 were applied to the Geo-SOMs. Considering the consistency of data variation among different levels of geographic tolerances, as well as accordance with real geographical and environmental conditions, we chose the value $k$ $=0$ for the output.

We determined the initial number of nodes as $5 \sqrt{ } \mathrm{n}$, according to Vesanto and Alhoniemi (2000). The number of nodes was adjusted through pre-training and $6 \times 9$ nodes were finally used as the SOM output layer. The learning rate was equal to 0.3 initially and decreased gradually to 0.1 as the training proceeded for fine tuning. In order to compare the Geo-SOM results with correlations, we also plotted correlation matrices using package ggplot 2 in R Software v3.2.3 (Wickham, 2016)

The input matrix for the Geo-SOM was composed of 250 (2014 2016) and 355 (2017) sample units and 11 (2014 2016) and 10 (2017) environmental variables. As stated above, the environmental variables were landscape, including altitude (ALT), distance to forest (DFO), canopy cover rate (CAN), riparian forest zones within home range (ZFO), and water zones within home range (ZWA); food sources, including BMI, FAI, and number of fish individuals (NFI); and anthropogenic factors, including distance to factory (DFA), distance to residence (DRE), and human population (POP). Position data, latitude (LAT) and longitude (LON), were also included as input data per sample site for training by the Geo-SOM.

\section{Results}

\subsection{Spraint Dispersal Patterns Based on Binary Data}

Figure 2 shows otter dispersal patterns when the diffusion kernel was applied to binary data (presence/absence) of spraint densities (see Materials and Methods) during the survey period from 2014 to 2017. The upper panel of Figure 2a presents dispersal patterns under homogenous environmental conditions, where the cost of travel for otters was equivalent throughout the survey area, while Figure $2 \mathrm{~b}$ considered the travel cost for otters under heterogenous environmental conditions (see 'Dispersal patterns based on diffusion kernel' in Materials and Methods). Two separate populations were observed in the north ( $\mathrm{N}$ population) and south-west ( $\mathrm{S}$ population) areas for both homogenous and heterogenous conditions. The centre area with the maximum occurrence probability was observed in the S population in 2014 (Figures 2a b), located in the survey area surrounding the Hapcheon dam river basin $\left(127.645^{\circ} \mathrm{E}\right.$ and $35.583^{\circ} \mathrm{N}$, arrow in Figure 2a). The pro- babilities according to the diffusion kernel in this area were continuously high across the survey period: initially the area of maximum occurrence probability was small and grew continuously as the survey proceeded (Figures $2 \mathrm{a} \sim \mathrm{b}$ ). In the $\mathrm{N}$ population, however, the centre area was not clearly observed for both homogenous and heterogenous conditions (Figures $2 \mathrm{a}$ $\sim$ b).

Dispersal pattern development differed between the two subpopulations as time progressed. While the $\mathrm{N}$ population spread somewhat horizontally from west to east with occurrence probabilities extending broadly in the eastern area and then further dispersed to the south, the $\mathrm{S}$ population dispersal was limited to the left region of the south, bound by the industrial belt connecting Gumi-Daegu-Changwon north to south (see white dotted ellipses, Figures $2 \mathrm{a} \sim \mathrm{c}$ ). Notably, the $\mathrm{S}$ and $\mathrm{N}$ population merged in 2016 and separated again in 2017 under homogenous environmental conditions (dotted ellipse in the right panel, Figure 2a).

When the cost of travel was accounted for in the diffusion kernel method (i.e., higher cost associated with urban areas), as outlined in Figure $2 \mathrm{~b}$ (see Materials and Methods), the general pattern was similar to the case of a homogeneous environment: two subpopulations were divided into northern and southern areas and then merged in 2016 (Figure 2b). However, differences were also observed. Overall, as expected, the industrial and city areas had lower occurrence probabilities predominant across the north-south industrial belt connecting Gumi, Daegu, and Changwon, as stated above. Further, lower otter occurrence probabilities were observed in the additional belt connecting Pohang, Ulsan, and Busan from north to south on the east coast of the survey area as well (see high levels of urbanisation (red colour) in the eastern coastal area, Figure 2c). Separation on the Gumi-Daegu-Changwon belt in the middle of the survey area was consistently observed throughout the survey area, including the heterogenous environment of 2016 (Figure 2b) when two populations were characteristically connected in the homogenous environment (Figure 2a).

Based on the dispersal kernel method applied to both homogenous and heterogenous environments, otter populations were prevalent during the survey period. But further expansions were observed during the study period in areas of low occurrence probabilities, confirming a full population recovery in the final phase (Hong et al., 2017). Due to the combination of the two subpopulations in 2016, populations further extended into local areas of low occurrence probabilities (Figure 2).

\subsection{Spatial Patterns of Environment-Spraint Relationships according to Geo-SOM}

In order to address impacts of environmental factors on otter populations during the survey period, a machine learning technique was applied to analyse the complex data exhibiting the existing relationships between spraint densities and environmental factors. Geo-SOM presented associative patterns between spraint and environmental data effectively on the 

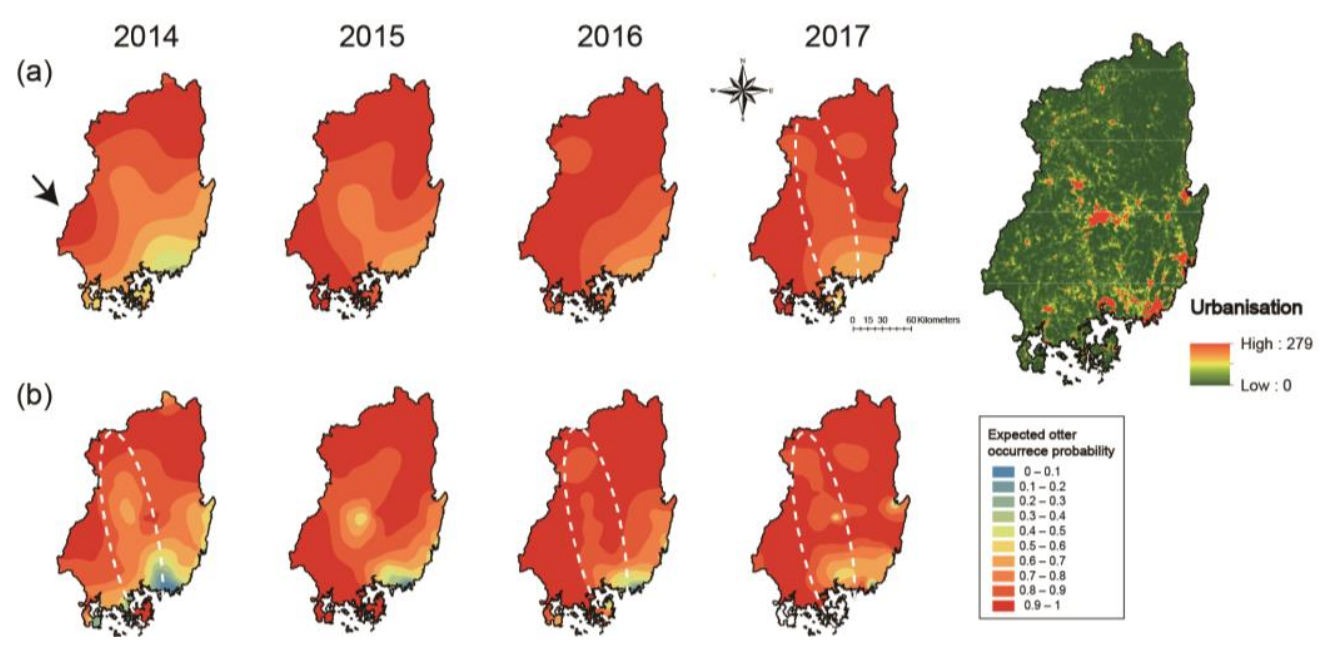

Figure 2. (a) Four maps of binary data using diffusion kernel estimations. Arrows indicate origin of S population. (b) Four maps using diffusion kernel estimations with additive barriers (urban area densities). (c) Urban area densities. Red and green colours represent high and low levels of urbanisation, respectively. White dotted circles in the fourth map of panel (a), first, third, and fourth maps of panel (b), and map (c) indicate the industrial belts (Gumi, Daegu, and Changwon).

(a)
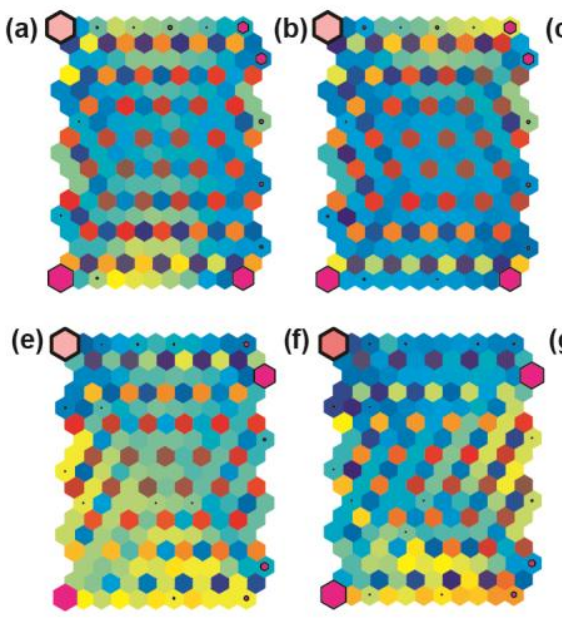

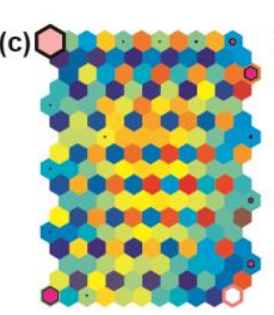

(g)

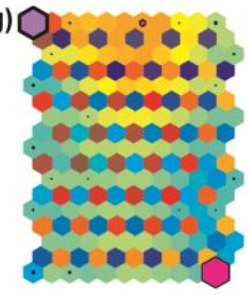

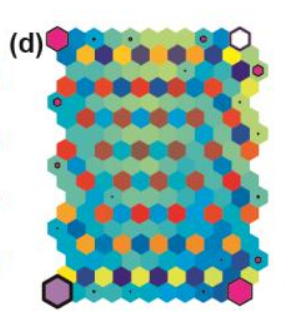

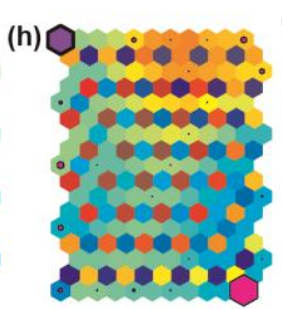

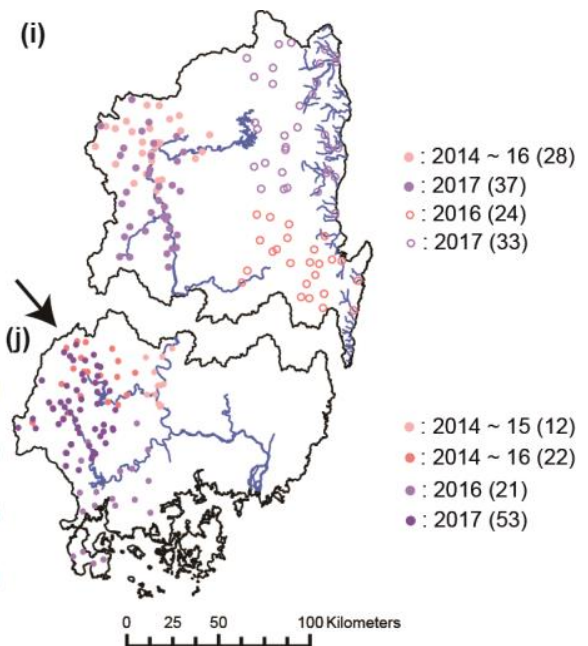

Figure 3. U matrices for N population in (a) 2014, (b) 2015, (c) 2016, and (d) 2017; and S population in (e) 2014, (f) 2015, (g) 2016, and (h) 2017. Sites clustered with high abundance of spraint densities in (i) N population and (j) S population. Hexagons ranging from light to deep purple and outlined in black indicate the strongest spatial clusters from earlier (2014) to later (2017) survey years, corresponding to study sites with the same-coloured circles in legend labels ( $i$ and $j$ ). Open white circles outlined in corresponding colours for each year indicate highest regional spraint density clusters (c, d) and sites (i). The arrow indicates the origin of the $\mathrm{S}$ population.

ordination map (Figure 3; See 'Application of Geo-SOM to identify spraint density relationships' section in Materials and Methods). The odd and even lines (columns and rows) on the ordination map indicate the SOM output nodes and U-Matrix (Ultsch and Siemon, 1990). The different sizes of hexagons on the odd lines indicate clusters of sample sites on Geo-SOM (in this case, mainly located at the corners of the maps), while the colours on the even lines represent the U-matrix, with bright tones (e.g., yellow and orange) indicating a greater distance between the nodes (Ultsch and Siemon, 1990). The largest clusters with the highest number of sample sites on the ordination map (Figures $3 \mathrm{a} \sim \mathrm{d}$ and $3 \mathrm{c} \sim \mathrm{h}$ ) are surrounded by black outlines. In the S population, the clusters corresponding to the largest group of sample sites were consistently observed at the top left corner of the SOMs, which correspond to the area of the Hapcheon dam river basin, as presented by the arrow in Figure 3j, as well as in Figure 2a displaying the dispersal kernel method.

In the $\mathrm{N}$ population, the cluster of the largest group of sample sites was located primarily in the top left corner until 2016 (Figures 3a c), occupying the Mungyeoung area in the north-west region of the survey period (see closed circles of 
pink tone, Figure 3i). The cluster of the largest group changed to the bottom left corner of the map in 2017 (Figure 3d), corresponding to the western part of the survey area (see closed circles of purple tone, Figure $3 \mathrm{i}$ ). In the $\mathrm{N}$ population, the cluster showing the highest level of spraint density was separately grouped in 2016 and 2017. These clusters were white hexagons outlined with light and deep purple colour (Figure $3 \mathrm{c}$ (bottom right) and 3d (top right), respectively) on the component plane, and also correspondingly represented as open circles in the bottom-right and top-right corners of geographic maps in 2016 and 2017, respectively (Figure 3i). These results indicated variations in population dispersal were observed to a greater extent in the eastern area for the $\mathrm{N}$ population.

The U-Matrix in the Geo-SOM further exhibited overall data variation during the survey period. In both populations, significant changes in data variation occurred during 2016 (Figure 3). In the $\mathrm{N}$ population, the levels of variation were low overall in $2014 \sim 2015$, but demonstrated the highest variation the following year in 2016, and decreased again the next year in 2017, according to the overall variation of U-Matrix values (see 'Application of Geo-SOM to identify spraint density relationships' section in Materials and Methods; Figures $3 \mathrm{a} \sim \mathrm{d})$. Similarly, data variation in the $\mathrm{S}$ population was relatively low in $2014 \sim 2015$ and increased significantly beginning in 2016 (Figures $3 \mathrm{a} \sim \mathrm{c}$ ). Notably, the data variation was relatively high in the bottom area of the SOMs during the early period of $2014 \sim 2015$ but did not increase in the upper area until the late period of $2016 \sim 2017$ for the $S$ population on the ordination map (Figures $3 \mathrm{e} \sim \mathrm{h}$ ). These results highly correlated with the change in environmental associations during the dispersal.

The associations between spraint densities and environmental factors are presented on the SOM component plane, which visualises the effect of environmental factors used in this study (Figure 4). According to the Geo-SOM training, position information at the sample sites are provided in Figures $4 \mathrm{a} \sim \mathrm{h}$, matching actual locations shown in Figure $3 \mathrm{i}$ and Figure $3 \mathrm{j}$ for the $\mathrm{N}$ and $\mathrm{S}$ populations, respectively. In the $\mathrm{N}$ population, through comparison of the sample positions, longitude (LON) and latitude (LAT), with the otter populations (OTT), the maximum density areas were found to be approximately consistent with the northern area, high LON, in 2014 and 2015 (vertical arrows in Figures 4a b). However, the highest spraint density area matched exactly with the high LAT (vertical arrow in Figure 4c) and partially with the low LON (oblique arrow in Figure 4c) in 2016. This area also corresponded with the location of highest spraint density observed on the Geo-SOM component plane (white hexagons outlined in light purple in Figure 3c) and was presented in the actual map (open circle outlined in light purple in Figure 3i). Similarly, in the following year (2017), the maximum spraint density area corresponded to both high levels of LAT and LON (Figure 4d), consistent with the Geo-SOM ordination map (open hexagon outlined in deep purple in Figure 3d) and actual geographic area in the north-east region (Figure 3i). In the $\mathrm{S}$ population, high spraint densities continuously corresponded with low LAT and high LON except in 2016 (verti- cal (close association) and oblique (partial association) arrows in Figures $4 \mathrm{e} \sim \mathrm{h}$ ), consistent with the north-west region on the ordination map (Figures $3 \mathrm{e} \sim \mathrm{h}$ ) and the actual geographic area (Figure 3j).

Data variation displayed in the U-Matrix of Figure 3 was reflected by the changes in association patterns observed in the component map between the spraint densities and environmental factors during the survey period (Figure 4). Notably, the association patterns substantially differed before and after 2016, as outlined in Figure 4. In the N population, OTT was primarily positively related to DFA and BMI, and negatively to POP and DFO in 2014 (Figure 4a). This trend similarly continued until 2015, with the exception of BMI (Figure 4b). The observed associations, however, differed in 2016; OTT was highly correlated with food sources, positively with NFI and CAN, indicating that the otter population was more concentrated on the food sources than anthropogenic factors in this year (Figure 4c). In the last year of 2017, otter populations were characteristically associated with most of the environmental factors, positively with BMI, FAI, ALT, and ZFO, and negatively with POP, DFO, and ZWA (Figure 4d).

In the $\mathrm{S}$ population, the anthropogenic factors were also a main constraint for the otter populations (Figures $4 \mathrm{e} \sim \mathrm{f}$ ) initially, positively associated with DFA and DRE, and negatively with POP and DFO, continuing this trend until 2015. Substantial changes were observed in associations between spraint densities and environmental factors in 2016 onwards. In the later period of $2016 \sim 2017$, spraint densities correlated with most of the environmental factors either positively or negatively for the $\mathrm{S}$ population, including food sources such as BMI, FAI, and NFI (Figures $4 \mathrm{~g} \sim \mathrm{h}$ ). This close association with environmental factors was in accordance with the associations observed in the N population during 2017 (Figure 4d).

The associations between spraint densities and environmental factors were consistent with the data variation observed on the Geo-SOM ordination map in Figure 3. The substantial change in the diffusion kernel exhibited during 2017 was also reflected in association patterns between spraint densities and environmental factors. The combination of the two sub-populations in 2016 (Figure 2) corresponded with the characteristic associations of most environmental factors on the component plane (Figure 4). The associations occurred earlier for the $\mathrm{S}$ population in 2016 and later for the $\mathrm{N}$ population in 2017. The late appearance of the characteristic association in the $\mathrm{N}$ population could be explained by the continuous population variability, including changes in associated environmental factors during 2016, over a broad area (Figures $2 \mathrm{a} \sim \mathrm{b}$ ) and data variation observed in the U-Matrix between 2016 and 2017 for the $\mathrm{N}$ population (Figures $3 \mathrm{c} \sim \mathrm{d}$ ).

Correlations between spraint densities and environmental factors are provided in Appendix S5 for comparison of the Geo-SOM results. Correlation coefficients of landscape and food resources were high overall, as observed in the SOM results. In the $\mathrm{N}$ population, for instance, spraints exhibited a relatively strong correlation to the food source, including BMI and FAI, and the landscape, including altitude and a negative 


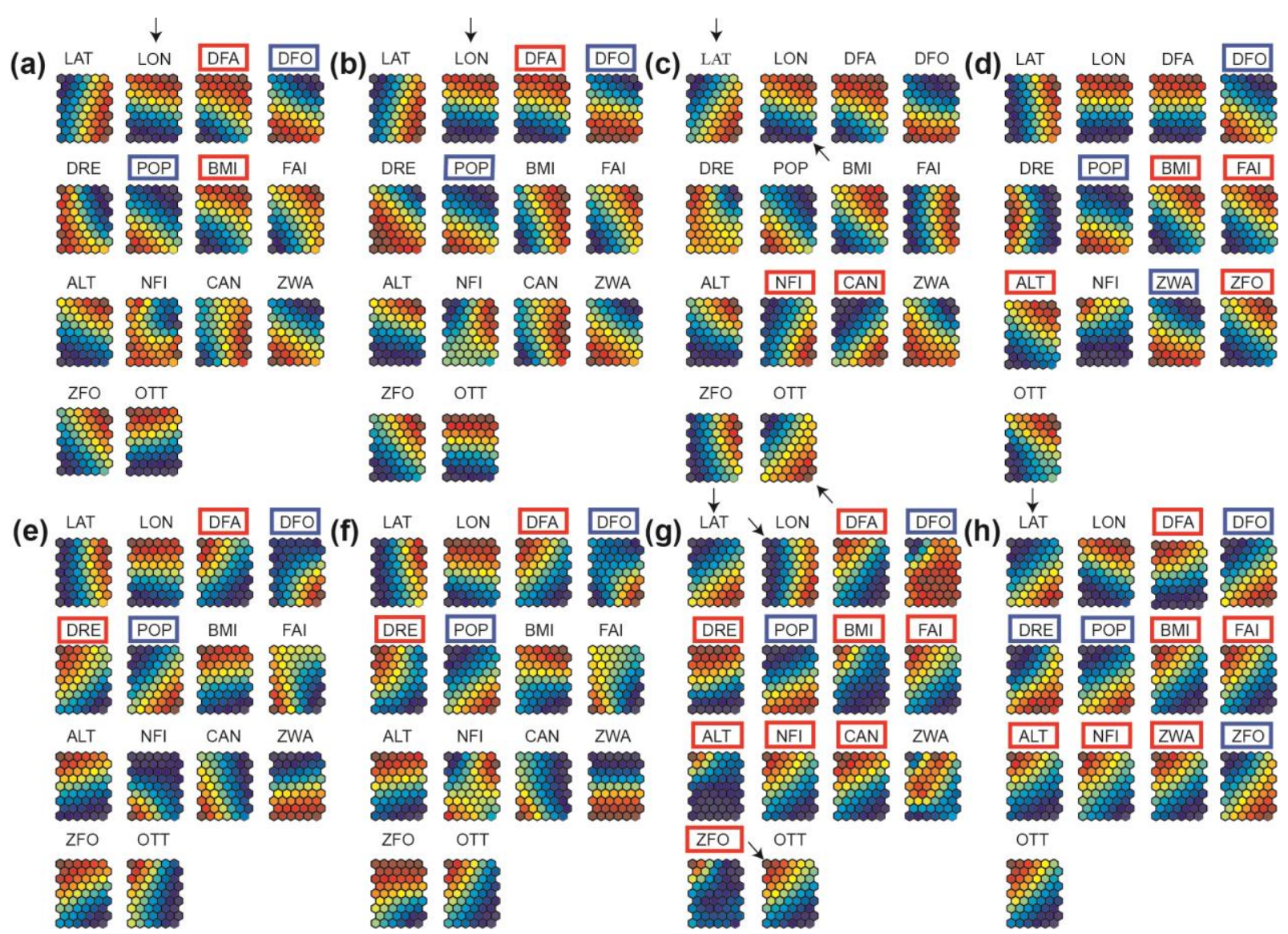

Figure 4. Component maps for N population in (a) 2014, (b) 2015, (c) 2016, and (d) 2017; and S population in (e) 2014, (f) 2015, (g) 2016, and (h) 2017. Red and blue rectangles outside of the abbreviated environmental factors indicate positive and negative relationships with spraint densities, respectively. All arrows correspond to the coordinate information, latitude (LAT) and longitude (LON), with higher spraint density areas. The values of all variables on the component planes were normalized between 0 (blue) and 1 (red).

association with ZWA, although the levels were generally low. In the $\mathrm{S}$ population, spraints exhibited a relatively weak correlation with environmental factors, but relatively high positive correlations with FAI and altitude, and a high negative correlation with ZWA. In the Geo-SOM map, however, associations with environmental factors were more finely addressed according to the $\mathrm{N}$ and $\mathrm{S}$ populations over the course of dispersal, as stated above. The correlations generally confirmed the results between spraint densities and environmental factors.

\section{Discussion}

Remarkably, over the last 30 years otter populations have been recovered across the southern peninsula of Korea (Hong et al., 2017). The current study presents the recent development patterns of otter populations during the last phase of full recovery for the survey period from 2014 to 2017. Although otter populations were prevalent, there were less invaded local areas, and otters continued to spread to the areas of low occurrence probabilities during the survey period, as indicated by the diffusion kernel method (Figure 2).

We portrayed changes in the dispersal patterns of otter populations using spraint data. First, we transformed the continuous spraint data into binary data for application of the diffusion kernel method to minimise quantitative errors that may be caused by continuous spraint densities in representing population size (see 'Dispersal patterns based on diffusion kernel' section in Materials and Methods). The diffusion kernel method applied to binary data accordingly presented population dispersal patterns: two subpopulations disparately advancing towards the area of low occurrence probabilities. Notably, a substantial change in population dispersal was observed in 2016 (Figure 2), which was the same year N and S populations merged, as observed for both homogenous and heterogenous environmental conditions. This substantial change in population states was further reflected in the results obtained from Geo-SOM (Figures 3 and 4). In the merging year of 2016, data variation occurred extensively on the U-Matrix (Figure 3). The characteristic associations with most environmental factors were observed on the Geo-SOM component plane (Figure 4). Considering the supportive data variation 
observed in the Geo-SOM, the results obtained by applying the kernel method to the binary data are reliable in addressing the dispersal patters during the last phase of full recovery.

The issue of utilising quantitative spraint density data for the representation of otter populations is still debatable (Kruuk and Conroy, 1987; Mowry et al., 2011). Based on the results stated above, we are in the position to propose the possibility of using spraint densities to demonstrate population dispersal patterns. First, we use the binary data (presence/absence) of spraint densities and accordingly minimise the quantitative errors caused by spraint densities (e.g., reflecting activity rather than representing population densities). The binary data could be used as a means of relative density, and to effectively present the increasing population trend (i.e., not necessarily estimating absolute population densities). If a sufficient amount of presence and absence data could be observed over a broad area for a long period under the same protocol, the diffusion kernel method could be used to present the population dispersal trend, as presented in Figure 2. Additionally, there is a report that the spraint data could directly represent otter populations' densities proportionally. Mowry et al. (2011) demonstrated that population densities are linearly proportional to spraint densities $\left(r^{2}=0.58\right)$, as stated above.

We also observed the increasing trend of spraint density during the survey period. Figure 5 illustrates an increase in average spraint densities for different years. Spraint densities grew rapidly for two consecutive years in the latter part of the survey period, 2016 and 2017. The S population monotonically increased from 2014 while the $\mathrm{N}$ population slightly decreased from 2014 to 2015, before rapid increase in spraint densities over the following years. Notably, continuous increase in spraint densities occurred concurrently with the merge of two subpopulations in 2016, according to the diffusion kernel method (Figure 2) and the change in relationship patterns between spraints and environmental factors in the latter period of the survey for both populations (Figures 3 and 4). Overall, the spraint densities adequately represented otter populations in Korea during the last phase of full recovery (Hong, 2018).

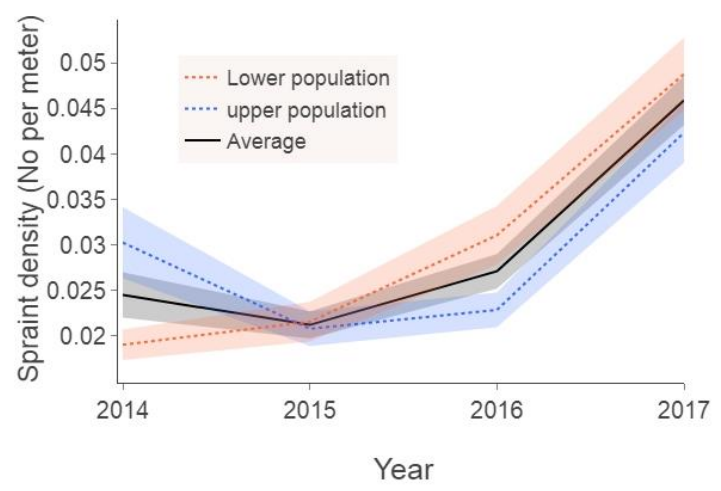

Figure 5. Spraint densities comparing the average (black line), $\mathrm{S}$ population (dotted red line), and $\mathrm{N}$ population (dotted blue line). Lightly coloured areas represent the standard error of each line.
Assuming that spraint data are proportional to otter population densities (Mowry et al., 2011), we further tested applicability of the diffusion kernel to continuous spraint density data (Figure 6). Similar to the case of binary data, two separate populations were observed in the north and southwest areas. In general, dispersal patterns were more precisely addressed in the continuous data. Specifically, the origin was obtainable in the continuous data with a single peak in the centre area due to high occurrence probabilities. The origins of both populations could be identified, located in river basins, near Mungyeong in the Naeseong river basin $\left(128.392^{\circ} \mathrm{E}\right.$ and $36.789^{\circ} \mathrm{N}$ ) for the $\mathrm{N}$ population and Geochang in the Habcheon dam river basin $\left(127.645^{\circ} \mathrm{E}\right.$ and $\left.35.583^{\circ} \mathrm{N}\right)$ for the $\mathrm{S}$ population (two solid arrows on the left panel (2014) of Figure $6 \mathrm{a}$ ). Note, the origin of the $\mathrm{N}$ population was not identified with the binary data (Figure 2a).

Furthermore, the advancement trend was more precisely presented. Notably, a bud-shaped dispersal from west to east was located in the southeast area in 2016 over the course of advancement, indicating a partial intrusion eastward in the $S$ population (solid arrow in 2016, Figure 6a). This area corresponded with Yeongcheon $\left(127.686^{\circ} \mathrm{E}\right.$ and $35.741^{\circ} \mathrm{N}$, arrow in 2016, Figure 6a). A bud shape was additionally observed in 2015. The area was intruded again by the $\mathrm{N}$ population in 2017 (dotted arrow in 2017, Figure 6a). Three local high -density areas were further located and connected to each other (dotted arrows in 2017; Figure 6a), which eventually indicated invasion from north to south. These areas corresponded with Bonghwa, Yeoungdeuk, and Yeongcheon (white circles in Figure 6c).

When the cost of travel was accounted for in the diffusion kernel (i.e., higher cost associated with urban areas), as outlined in Figure 2b (see Materials and Methods), the general pattern was similar to the case of a homogeneous environment with eastward advancement (Figure 6a), followed by an overall occupation of the survey area in 2017. However, the contrast between low and high density in industrial and non -industrial areas, respectively, was clearer in the heterogeneous environment. Spraint densities were low in the industrial areas located in the southeast corner of the survey area, including Masan, Changwon, and Busan on the southern boundary; and Ulsan and Pohang on the eastern boundary (red colour tones, Figure 6c). The intrusion of the $\mathrm{N}$ population to the south was more pronounced in the heterogeneous environment. Spraint densities were highly connected to the local populations leading south compared with densities in the homogeneous environment (dotted arrows in 2017, Figure 6b). The west-to-east intrusion of the $\mathrm{S}$ population, however, appeared less robust in 2016, and was weakly connected to both populations (solid arrow in 2016, Figure 6b). This indicated that the heterogeneous environment supported the intrusion by the $\mathrm{N}$ population southward, rather than the eastward intrusion by the $S$ population.

We observed strong associations between the majority of environmental factors during the course of dispersal, in 2016 and 2017 for the S population (Figures $4 \mathrm{~g} \sim \mathrm{h}$ ), and in 2017 for the $\mathrm{N}$ population (Figure $4 \mathrm{~d}$ ). Habitat suitability was mainly 


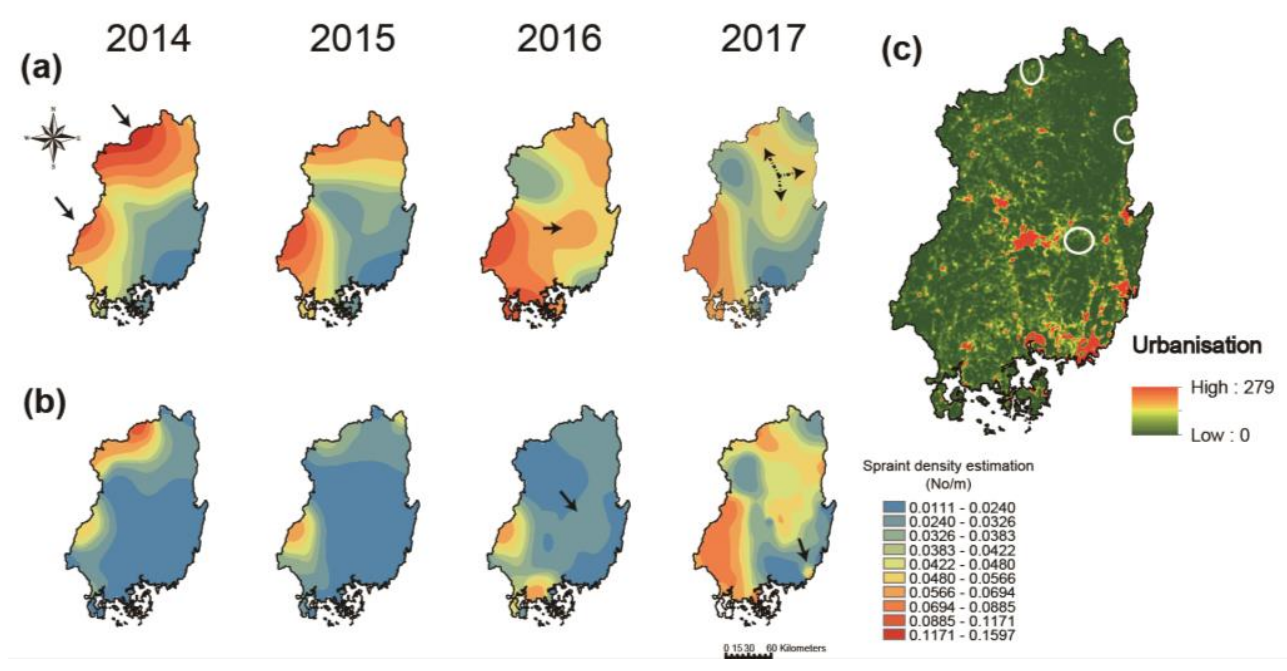

Figure 6. (a) Four maps using spraint densities data applying diffusion kernel estimations. (b) Four maps using diffusion kernel estimations with additive barriers (urban area densities). (c) Urban area densities. Red and green colours represent high and low levels of urbanisation, respectively. Arrows in the first map of upper panel (a) indicate the origin of each population, and third map of panel $(a, b)$ indicate the combined area between the two populations. Dotted arrows in the fourth map of ( $a, b)$ suggest small regional populations. White circles in land cover map (c) represent the areas corresponding to all arrows of the third and fourth maps $(a, b)$.

constrained by anthropogenic factors during the initial advancement phase, and later correlated with all other factors, including food, as population stabilized (Figure 4). This confirmed previous studies reporting that urban areas serve as barriers against otter population dispersal (Marcelli and Fusillo, 2009). In our study, we further addressed that a complete relationship between spraint data and various factors, including food sources and environmental factors, could be demonstrated during the course of recovery. This substantial relationship with environmental conditions over specific years indicates that the populations were further stabilized and closely related to food sources, even over a short period during the last phase of recovery. In the $S$ population, stability was more apparent in the two years of 2016 and 2017. The stability was observed faster in the $\mathrm{S}$ population, which had a short range of dispersal, bounded by the industrial area (lower panels, Figure 2 and Figure 6). We observed that population development could be stabilized regarding close associations with environmental factors during the last phase of the dispersal.

One of problems with field surveys was the change in sample sites in 2017 (see 'Spraint density measurement' section in Materials and Methods). In 2016, CAN was related to spraint densities in both $\mathrm{N}$ and $\mathrm{S}$ populations. In following year of 2017, the environmental variable, CAN, was neither measured due to research conditions (Figure 6). Although the sample sites and variable varied partially with the 2017 survey, the results regarding diffusion processes would be unlikely different. Considering that the diffusion kernel method is applied to the whole data set in order to address overall dispersal patterns at the population level, the dispersal patterns delivered essential information in general and portrayed the trend of results from the previous years (Figure 2a).

\section{Conclusion}

Based on diffusion kernel and artificial neural networks (Geo-SOM), the dispersal patterns of otter populations were specifically characterized for the last phase of full recovery in Korea over a relatively short period, showing two geographically separated populations. When the diffusion kernel method was applied to both binary and continuous spraint data, dispersal patterns were accordingly addressed by the merge of the two subpopulations in 2016. While the north (N) population moved broadly eastward and southward, achieving prevalence throughout the Nakdong River basin by 2017, dispersal of the south (S) population was limited by the industrial area located in the south-east region of the survey area. Under the condition of a heterogeneous environment considering travel costs, the occurrence probabilities were further constrained by the industrial and populated areas. The Geo-SOM revealed associations between spraint densities and environmental factors, concurrently linking geographic locations of sample sites. Both populations were affected by anthropogenic factors, including distance to factory and human population density. But associations with all environmental factors, including landnscape, food sources, and anthropogenic factors appeared more pronounced when populations further dispersed in the later period of the survey, demonstrating the changes in population states over the course of dispersal during full recovery. Overall, the associations with environmental factors could be determined according to the specific constraints in the places where otter populations were located (e.g., industrial area) and at the time when populations became stabilized. This study demonstrates that the combined use of the diffusion kernel method and Geo-SOM was effecttive in portraying temporal changes in population states in association with environmental 
factors based on stationary spraint data in the last phase of full recovery.

Acknowledgements. This work was supported by the both grants from the 'Basic Research (NRF-2016R1D1A1B01009492)' and 'NRF -2015-Fostering Core Leaders of the Future Basic Science Program/ Global Ph.D. Fellowship Program (2015H1A2A1034384)' supported by an NRF (National Research Foundation of Korea).

\section{References}

Bação, F., Lobo, V. and Painho, M. 2004. Geo-self-organizing map (Geo-SOM) for building and exploring homogeneous regions. In Egenhofer, M.J., Freksa, C., and Miller, H.J. (Eds.), Geogr Inf Sci., 3234. 22-37. https://doi.org/10.1007/978-3-540-30231-5_2

Bação, F., Lobo, V. and Painho, M. 2005. Geo-SOM and its integration with geographic information systems. Proc. of the 5th Workshop on Self-Organizing Maps, Paris., 5-8

Barbosa, A.M., Real, R., Olivero, J., and Vargas, J.M. 2003. Otter (Lutra lutra) distribution modeling at two resolution scales suited to conservation planning in the Iberian Peninsula. Biol Conserv., 114, 377-387. https://doi.org/10.1016/S0006-3207(03)00066-1

Boulanger, J.G., and White, G.C. 1990. A comparison of home-range estimators using Monte Carlo simulation. J Wildlife Manage., 54, 310-315. https://doi.org/10.2307/3809048

Botev, Z.I., Grotowski, J.F., and Kroese, D.P. 2010. Kernel density estimation via diffusion. Ann Stat., 38, 2916-2957. https://doi. org/10.1214/10-AOS799

Blundell, G.M., Maier, J.A. and Debevec, E.M. 2001. Linear home ranges: effects of smoothing, sample size, and autocorrelation on kernel estimates. Ecol Monogr., 71, 469-489. https://doi.org/10. 1890/0012-9615(2001)071[0469:LHREOS]2.0.CO;2

Calhoun, J.B., and Casby, J.U. 1958. Calculation of home range and density of small mammals. Public Health Monograph Number 55, United States Department of Health, Education, and Welfare.

Chen, S.X. 1996. A kernel estimate for the density of a biological population by using line transect sampling. J R Stat Soc C-Appl., 45, 135-150. https://doi.org/10.2307/2986150

Cho, H.S., Choi, K.H., Lee, S.D., and Park, Y.S. 2009. Characterizing habitat preference of Eurasian river otter (Lutra lutra) in streams using a self-organizing map. J Limnol., 10, 203-213. https://doi. org/10.1007/s10201-009-0275-7

Chon, T.-S., Park, Y.S., Moon, K.H., and Cha, E.Y. 1996. Patternizing communities by using an artificial neural network. Ecol Model., 90, 69-78. https://doi.org/10.1016/0304-3800(95)00148-4

Chon, T.S., Park, Y.S., and Park, J.H. 2000. Determining temporal pattern of community dynamics by using unsupervised learning algorithms. Ecol Model., 132, 151-166. https://doi.org/10.1016/ S0304-3800(00)00312-4

Chon, T.-S. 2011. Self-organizing maps applied to ecological sciences. Ecol Inform., 6, 50-61. https://doi.org/10.1016/j.ecoinf. 2010.11.002

Clavero, M., Hermoso, V., Brotons, L., and Delibes, M. 2010. Natural, human and spatial constraints to expanding populations of otters in the Iberian Peninsula. J Biogeogr., 37, 2345-2357. https://doi.org/ 10.1111/j.1365-2699.2010.02377.x

Conroy, J., Melisch, R., and Chanin, P. 1998. The distribution and status of the Eurasian otter (Lutra lutra) in Asia-a preliminary review. IUCN Otter Specialist Group Bullentin., 15, 15-30

Conroy, J.W., and Chanin, P.R. 2000. The status of the Eurasian otter (Lutra lutra) in Europe. A Review. J IOSF., 1, 7-28

Cortés, Y., Fernández-Salvador, R., García, F., Virgós, E., and Llorente. M. 1998. Changes in otter Lutra lutra distribution in Central Spain in the 1964-1995 period. Biol Conserv., 86, 179-183. https://doi.org/10.1016/S0006-3207(98)00009-3
De Smith, M.J., Goodchild, M.F., and Longley, P. 2007. Geospatial analysis: a comprehensive guide to principles, techniques and software tools. Winchelsea Press.

Doucet, A., de Freitas, N., and Gordon, N. 2001. An introduction to sequential Monte Carlo methods in practice. Springer. https:// doi.org/10.1007/978-1-4757-3437-9

EGIS. Environmental Geographic Information Service (Republic of Korea). https://egis.me.go.kr (accessed Mar 24, 2018)

Elmeros, M., Hammershoj, M., Madsen, A., and Sogaard, B. 2006. Recovery of the otter Lutra lutra in Denmark monitored by field surveys and collection of carcasses. Hystrix., 17, 17-28. https://doi. org/10.4404/hystrix-17.1-4361

Erlinge, S. 1967. Home range of the otter Lutra lutra L. in southern Sweden. Oikos., 18, 186-209. https://doi.org/10.2307/3565098

Gautestad, A.O., and Mysterud, L. 1993. Physical and biological mechanisms in animal movement processes. J Appl Ecol., 30, 523-535. https://doi.org/10.2307/2404192

Green, J., Green, R., and Jefferies, D.J. 1984. A radio-tracking survey of otters Lutra lutra on a Perthshire river system. Lutra., 27, 85-145

Hayne, D.W. 1949. Calculation of size of home rage. J Mammal., 30, 1-18. https://doi.org/10.2307/1375189

Hong, S. 2016. Re-establishment of the Eurasian otter (Lutra lutra) in South Korea from 1987 to 2010: the contributions of environmental improvement and conservation policy. 13th International Otter Congress, Singapore

Hong, S. 2018. Habitat, dispersal and management of semi-aquatic mammals in Republic of Korea. Ph.D. Dissertation, Pusan National University, Pusan, South Korea

Hong, S., Do, Y., Kim, J.Y., Cowan, P., and Joo, G.J. 2017. Conservation activities for the Eurasian otter (Lutra lutra) in South Korea traced form newspapers during 1962-2010. Biol Conserv., 210, 157-162. https://doi.org/10.1016/j.biocon.2017.03.010

Hong, S., Kim, D.K., Do, Y., Kim, J.Y., Kim, Y.M., Cowan, P., and Joo, G. J. 2018. Stream health, topography, and land use influences on the distribution of the Eurasian otter Lutra lutra in the Nakdong River basin, South Korea, Ecol Indic., 88, 241-249. https:// doi.org/10.1016/j.ecolind.2018.01.004

Hutchings, M.R., and White, P.C.L. 2000. Mustelid scent-marking in managed ecosystems: implications for population management. Mammal Rev., 30, 157-169. https://doi.org/10.1046/j.1365-2907. 2000.00065.x

Janssens, X., Defourny, P., De Kermabon, J., and Baret, P. 2006. The recovery of the otter in the Cevennes (France): a GIS-based model. Hystrix., 17, 5-14. https://doi.org/10.4404/hystrix-17.1-4360

Jeong, K.S., Kim, D.K., and Joo, G.J. 2007. Delayed influence of dam storage and discharge on the determination of seasonal poliferations of Microcystis aeruginosa and Stephanodiscus hantzschii in a regulated river system of the lower Nakdong River (South Korea). Water Res., 41, 1269-1279. https://doi.org/10.1016/ j.watres.2006.11.054

Jo, Y.S., Won, C.M., Frittes, S.R., Wallace, M.C., and Baccus, J.T. 2017. Distribution and habitat models of the Eurasian otter, Lutra lutra, in South Korea. J Mammal., 98, 1105-1117. https://doi.org/ 10.1093/jmammal/gyx037

Keeling, M.J., Brooks, S.P., and Gilligan, C.A. 2004. Using conservation of pattern to estimate spatial parameters from a single snapshot. P Natl Acad Sci USA., 101, 9155-9160. https://doi. org/10.1073/pnas.0400335101

Kohonen, T. 1982. Self-organized formation of topologically correct feature maps. Biol Cybern., 43, 59-69. https://doi.org/10.1007/ BF00337288

Kondor, R., and Lafferty, J. 2004. Diffusion Kernels on graphs and other discrete input spaces. In Scholkopf, B., Tsuda, K., and Vert, J.P. (Eds), Kernel Methods in Computational Biology. The MIT Press., pp. 315-322 
Krivoruchko, K., and Gribov, A. 2002. Geostatistical interpolation and simulation with non-euclidean distances. In Sanchez-Villa, X., Carrera, J., and Gomeaz-Hernandez, J.J. (Eds). geoENV IV, Kluwer Academic Publishers., 331-342 https://doi.org/10.1007/1-40202115-1_28

Kruuk, H. 2006. Otters: ecology, behavior and conservation. Oxford University Press., https://doi.org/10.1093/acprof:oso/97801985658 71.001.0001

Kruuk, H., and Conroy, J.W.H. 1987. Surveying otter Lutra lutra populations: A discussion of problems with spraints. Biol Conserv., 41, 179-183. https://doi.org/10.1016/0006-3207(87)90101-7

Loehle, C. 1990. Home range: a fractal approach. Landscape Ecol., 5, 39-52. https://doi.org/10.1007/BF00153802

Marcelli, M., and Fusillo, R. 2009. Assessing range re-expansion and recolonization of human-impacted landscapes by threatened species: a case study of the otter (Lutra lutra) in Italy. Biodivers Conserv., 18, 2941-2959. https://doi.org/10.1007/s10531-009-96 18-2

Mason, C.F., and Macdonald, S.M. 2004. Growth in otter (Lutra lutra) populations in the UK as shown by long-term monitoring. AMBIO., 33, 148-152. https://doi.org/10.1579/0044-7447-33.3.148

Min, H. 2007. Studies on the behavior ecology and habitat environment of Eurasian otter (Lutra lutra) by Radio tracking. Ph.D. Dissertation, Gyeongsan National University, Jinju, South Korea

MOE/NIER. 2017. Survey and Evaluation of Aquatic Ecosystem Health in Korea. The Ministry of Environment/National Institute of Environmental Research

Mowry, R.A., Gompper, M.E., Beringer, J., and Eggert, L.S. 2011. River otter population size estimation using non-invasive latrine surveys. J Wildlife Manage., 75, 1625-1636. https://doi.org/10.10 02/jwmg. 193

Naef-Daenzer, B. 1993. A new transmitter for small animals and enhanced methods of home-range analysis. J Wildlife Manage., 57, 680-689. https://doi.org/10.2307/3809066

Prenda, J., López-Nieves, P., and Bravo, R. 2001. Conservation of otter (Lutra lutra) in a Mediterranean area: the importance of habitat quality and temporal variation in water availability. Aquat Conserv., 11, 343-355. https://doi.org/10.1002/aqc.454

Prigioni, C., Remonti, L., Balestrieri, A., Sgrosso, S., Priore, G., Misin, C., Viapiana, M., Spada, S., and Anania, R. 2005. Distribution and sprainting activity of the Otter (Lutra lutra) in the Pollino National Park (southern Italy). Ethol Ecol Evol., 17, 171-180. https://doi.org/10.1080/08927014.2005.9522606

Prigioni, C., Balestrieri, A., and Remonti, L. 2007. Decline and recovery in otter Lutra lutra populations in Italy. Mammal Rev., 37, 71-79. https://doi.org/10.1111/j.1365-2907.2007.00105.x

Robitaille, J.F., and Laurence, S. 2002. Otter, Lutra lutra, occurrence in Europe and in France in relation to landscape characteristics. Anim Conserv., 5, 337-344. https://doi.org/10.1017/S13679430020 04109

Rostain, R.R., Ben-David, M., Groves, P., and Randall, J.A. 2004. Why do river otters scent-mark? An experimental test of several hypotheses. Anim Behav., 68, 703-711. https://doi.org/10.1016/j.an behav.2003.10.027

Ruiz-Olmo, J., Margalida, A., and Gatet, A. 2005. Use of small rich patches by Eurasian otter (Lutra lutra L.) females and cubs during the pre-dispersal period. $J$ Zool., 265, 339-346. https://doi.org $/ 10.1017 /$ S0952836905006424

Ruiz-Olmo, J., and Jiménez, J. 2009. Diet diversity and breeding of top predators are determined by habitat stability and structure: a case study with the Eurasian otter (Lutra lutra L.). Eur J Wildlife Res., 55, 133-144. https://doi.org/10.1007/s10344-008-0226-3

Ruiz-Olmo, J., Batet, A., Mañas, F., and Martínez-Vidal, R. 2011. Factors affecting otter (Lutra lutra) abundance and breeding success in freshwater habitats of the northeastern Iberian Peninsula. Eur J Wildlife Res., 57, 827-842. https://doi.org/10.1007/s10344011-0495-0

Scorpio, V., Loy, A., Di Febbraro, M., Rizzo, A., and Aucelli, P. 2016. Hydromorphology meets mammal ecology: river morphological quality, recent channel adjustments and otter resilience. River Res Appl., 32:267-279. https://doi.org/10.1002/rra.2848

Seaman, D.E., and Powell, R. A. 1996. An evaluation of the accuracy of kernel density estimators for home range analysis. Ecology., 77, 2075-2085. https://doi.org/10.2307/2265701

Silverman, B.W., 1986. Density estimation for statistics and data analysis. Chapman and Hall., https://doi.org/10.1007/978-1-48993324-9

Sjoasen, T. 1997. Movements and establishment of reintroduced European otters Lutra lutra. J Appl Ecol., 34, 1070-1080. https:// doi.org/10.2307/2405295

Teresa, C.M., Antoine, G., Carmen, C., Tiziana, S., Loy, A., and Laura, C.M. 2014. A multi-temporal approach to model endangered species distribution in Europe. The case of the Eurasian otter in Italy. Ecol Model., 274, 21-28. https://doi.org/10.1016/ j.ecolmodel.2013.11.027

Ultsch, A., and Siemon, H.P. 1990. Kohonen Networks on Transputers: Implementation and Animation. INNC., 2, 305-308

Van Looy, K., Piffady, J., Cavillon, C., Tormos, T., Landry, P., and Souchon, Y. 2014. Integrated modelling of functional and structural connectivity of river corridors for European otter recovery. Ecol Model., 273, 228-235. https://doi.org/10.1016/j.ecolmodel. 2013.11.010

Van Winkle, W. 1975. Comparison of several probabilistic homerange models. J Wildlife Manage., 39, 118-123. https://doi.org/10. $2307 / 3800474$

Vergara, M., Ruiz-González, A., de Luzuriaga, J.L., and GómezMoliner, B.J. 2014. Individual identification and distribution assessment of otters (Lutra lutra) through non-invasive genetic smpling: Recovery of an endagered species in the Basque Country (Northern Spain). Mamm Biol., 79, 259-267. https://doi.org/10.10 16/j.mambio.2014.04.003

Vesanto, J., and Alhoniemi, E. 2000. Clustering of the self-organizing map. IEEE T Neural Networ., 11, 586-600. https://doi.org/10.1109/ 72.846731

Webbon, C.C., Baker, P.J., and Harris, S. 2004. Faecal density counts for monitoring changes in red fox numbers in rural Britain. $J$ Appl Ecol., 41, 768-779. https://doi.org/10.1111/j.0021-8901-2004.009 30.x

Wickham, H. 2016. Ggplot2: Elegant graphics for data analysis. Springer-Verlag. https://doi.org/10.1007/978-3-319-24277-4

Won, C.M., and Smith, K.G. 1999. History and current status of mammals of the Korean peninsula. Mammal Rev., 29, 3-36. https://doi.org/10.1046/j.1365-2907.1999.00034.x

Zhang, R., Yang, L., Laguardia, A., Jiang, Z., Huang, M., Lv, J., Ren, Y., Zhang, W., and Luan, X. 2016. Historical distirubtion of the otter (Lutra lutra) in north-east China according to historical records (1950-2014). Aquat Conserv., 26, 602-606. https://doi. org/10.1002/aqc.2624 